\title{
Effect of Well Resistance on Time Factor Ratio Due to PVD Deformation
}

\author{
Galuh Chrismaningwang ${ }^{1,3 *}$, Hary Christady Hardiyatmo' ${ }^{1}$, Agus Darmawan Adi', \\ Teuku Faisal Fathani ${ }^{1,2}$ \\ ${ }^{1}$ Department of Civil and Environmental Engineering, Universitas Gadjah Mada, Yogyakarta, INDONESIA \\ JI. Grafika No. 2 Kampus UGM, Yogyakarta \\ ${ }^{2}$ Center for Disaster Mitigation and Technological Innovation (GAMA-InaTEK), Universitas Gadjah Mada, Yogyakarta, INDONESIA \\ JI. Grafika No. 2 Kampus UGM, Yogyakarta \\ ${ }^{3}$ Department of Civil Engineering, Faculty of Engineering, Universitas Sebelas Maret, Surakarta, INDONESIA \\ Jalan Ir. Sutami No. 36 A Surakarta \\ "Corresponding author: galuh.chrisma.n@mail.ugm.ac.id
}

SUBMITTED 27 February 2021 REVISED 2 May 2021 ACCEPTED 10 May 2021

ABSTRACT One of the most common soft soil enhancement techniques used to expedite the consolidation time significantly is Prefabricated Vertical Drains (PVD). This technique needs a sufficient discharge capacity value because it primarily functions as a drainage channel. The deformation of PVD is considered as one of the primary factors which affect discharge capacity. Therefore, this research determined the influence of upper-side deformation on PVD's discharge capacity $\left(q_{w}\right)$ using a specific design apparatus known as ASTM D4716, which manages the determination of transmissivity and flow rate at the longitudinal direction of geosynthetics. Furthermore, two PVD samples with dimensions of 3 and $4 \mathrm{~mm}$ thickness, $100 \mathrm{~mm}$ width, and $1000 \mathrm{~mm}$ length were examined under straight and buckled conditions. Stepwise confining pressures from 50 to $200 \mathrm{kPa}$ were subjected to the samples under hydraulic gradients with values of $0.2,0.5$, and 1.0 . The results showed that samples with greater thickness had higher discharge capacity, which significantly reduced in the lower hydraulic gradient. The deformation on the upper side of PVD induced a decrease of discharge capacity by approximately 13-16\%, which led to a delay in the consolidation time. The discharge capacity values obtained from the experiments were employed as parameters in a time factor ratio of $T_{\mathrm{h}, \mathrm{w}} / T_{\mathrm{h}}$. The analysis results show that the buckled PVD has a more considerable consolidation time due to the increase in the $T_{\mathrm{h}, \mathrm{w}} / T_{\mathrm{h}}$ ratio, with a discharge capacity value below $10^{-4} \mathrm{~m} 3 / \mathrm{s}$. It can be concluded that the deformation in the form of buckled conditions on the upper side of PVD had a considerable impact on PVD effectiveness.

KEYWORDS Consolidation, Discharge capacity; Geosynthetics; Soil improvement; Transmissivity; Preloading.

(c) The Author(s) 2021. This article is distributed under a Creative Commons Attribution-ShareAlike 4.0 International license.

\section{INTRODUCTION}

One of the most popular methods of enhancing soft soil in Indonesia is by using Prefabricated Vertical Drains (PVD). According to a research carried out by Hansbo (1979), PVD functions by shortening the drainage path to accelerates the soft soil consolidation time. In infield practice, PVD is often used alone or in combination with surcharge preloading, vacuum preloading, or Prefabricated Horizontal Drains (PHD). This method is considered more practical and economical than other soil improvement methods (Zhang, Ye, and $\mathrm{Xu}, 2018$; Da Silva et al., 2017). The efficiency of PVD depends on its discharge capacity, which is influenced by several factors, such as the opening of drainage channel area, the lateral earth pressure, the soft soil infiltration process, which tends to induce a clogging inside the core, and its deformation (Holtz, 1987).
Koerner (2005) stated that a variety of environmental concerns influences the flow rate of PVD. Over the past decades, comprehensive studies have been carried out on the discharge capacity of PVD influenced by deformation and confining pressures (Hansbo, 1997; Indraratna and Chu, 2005). For instance, Hansbo (1997) stated that the drains embedded at a considerable depth had a low discharge capacity value, leading to a consolidation time increase. Studies have also been conducted on the discharge capacity of PVD or PHD using ASTM or modified triaxial test apparatus. Bo et al. (2016) conducted laboratory works to analyze the factors that influenced PVD discharge capacity using straight and buckled drain testing devices. The research found that the discharge capacity reduced when the vertical pressure and the hydraulic gradients increased, significantly 
influencing hydraulic gradients on lower vertical pressure. Chrismaningwang et al. (2020) also carried out a research to determine the discharge capacity test using ASTM D4716 device and a short-term vertical pressure test using several types of PVD and PHD. The test results showed that PVD was more resistant to confining pressure compared to PHD. Furthermore, under $200 \mathrm{kPa}$ confining pressure, the discharge capacity of PHD was reduced by over $90 \%$. Jang et al. (2015) evaluated the influence of calcium carbonate filtration on the discharge capacity of geocomposite and various types of PVD using a discharge capacity test device modified from a triaxial test. The results showed that a harmonica-shaped core provided higher discharge capacity than the retiformed.

Studies on the effect of PVD deformation have also been extensively conducted, which concluded that the decrease in discharge capacity was reliant on the drain structure. Ali (1991) investigated the flow behavior of deformed PVD by combining the influence of lateral pressure and deformation of soil. The research showed that the discharge capacity reduction was affected by its geometrical structure and bending rigidity, while PVD with greater filter stiffness had better performance due to its resistance to lateral pressure. This research also concluded that the discharge capacity of PVD does not need to be established using the result of straight PVD since a large settlement tends to generate PVD deformation. Jeon (2014) conducted a short-term transmissivity test on bi-planar and tri-planar geonets. The results showed that the decrease of discharge capacity was determined by the structure of the geonet, with those comprising greater thickness had lower discharge capacity reduction. The results also showed that the decrease of geonet discharge capacity was significant when subjected to a pressure greater than $600 \mathrm{kPa}$. Tran-Nguyen et al. (2010) studied the impact of deformation on four types of PVD's discharge capacity with two types of soil as confining medium by conducting a laboratory measurement. Tran-Nguyen stated that for a project with a considerable settlement, the value of discharge capacity used on design is not solely dependent on the discharge capacity of straight PVD. The test also exhibited that hydraulic gradients were critically affected by discharge capacity reduction due to its influence on the type of water flow inside the PVD core. Cai et al. (2017) carried out a research on the experimental test results on deformed PVD installed in dredged soil with vacuum preloading. The vacuum pressure distribution on PVD has a bilinear relationship with the PVD deformation. On the other hand, research on upper-side PVD deformation with an extension above the soil has never been conducted. Therefore, this study examines the influence of upper-side deformation on the well resistance of PVD.

The buckled deformation imitated PVD condition is always buckled in the upper-side when worked alone or in combination with PHD. The value of PVD's well resistance was defined by measuring its discharge capacity, which is determined indirectly by conducting a laboratory measurement and using an apparatus designed according to ASTM D4716. It is also a method used to resolve the value of discharge capacity, transmissivity, and in-plane permeability of PVD by applying confining pressure under constant head flow conditions.

\section{DISCHARGE CAPACITY}

Discharge capacity $\left(q_{w}\right)$, is represented as the quantity of water discharge in the longitudinal directions with a particular hydraulic gradient (i) per unit time (Hansbo, 1979). According to Bourge`s-Gastaud, Blond, and Touze-Foltz (2013), Tripathi and Nagesha (2010), it is considered the most critical parameter in vertical drainage design and performance. Furthermore, Chung, Kweon, and Jang (2014) stated that the inaccurate estimation of consolidation rate is due to the incorrect input of discharge capacity value. Discharge capacity and the hydraulic gradient are defined in Equations (1) and (2).

$q_{w}=\frac{Q}{i}$
$i=\frac{\Delta h}{L}$ 
where, $Q$ denotes the rate of water flow within each unit of time $\left(\mathrm{m}^{3} / \mathrm{s}\right), i$ is the hydraulic gradient, $\Delta h$ is the difference of water head (m), and $L$ is the drainage length (m). In addition, $L$ is characterized as the specimen length.

The effectiveness of soil improvement using PVD depends on its discharge capacity, which needs to have a higher value than the surrounding soil's permeability value (Cascone and Biondi, 2013). Therefore, the closer the discharge capacity value to the soil's permeability, the greater the consolidation time. The value of well resistance depends on $k_{h} / q_{w}$, with the suggested values of required discharge capacity $\left(q_{\mathrm{w}(\text { req })}\right)$ higher than $3.2 \times 10^{-6}$ to $4.8 \times 10^{-6} \mathrm{~m}^{3} / \mathrm{s}$ (Holtz et al., 1991). The value of $q_{\mathrm{w}(\mathrm{req})}$ is defined in Equation (3), which was recommended by Mesri and Lo (1991).

$q_{w(r e q)}=5 k_{h} L^{2}$

where, $k_{h}$ is the surrounding soil's horizontal permeability $(\mathrm{m} / \mathrm{s})$, and $L$ is the maximum drainage flow length $(\mathrm{m})$.

\section{WELL RESISTANCE}

Well resistance is the product of horizontal soil permeability and discharge capacity $\left(k_{h} / q_{w}\right)$ function. The influence escalates when the value of discharge capacity reduces, which lead to a consolidation time increment, $t$, defined as a function of $\frac{T_{h} D^{2}}{c_{h}}$, where $T_{\mathrm{h}}$ is the factor of time, $D$ is the influence diameter value of $1.05 S$ for a triangular PVD formation or $1.13 S$ for a rectangular PVD formation, $S$ is the distance between each PVD, and $c_{\mathrm{h}}$ is the coefficient of horizontal consolidation. The value of the time factor is determined by using Equations (4) and (5), proposed by Barron (1948) and Hansbo (1979), respectively.

$T_{h}=\frac{\ln (1-U) F(n)}{-8}$
$T_{h, w}=\frac{\ln (1-U) F_{w}(n)}{-8}$

$U$ denotes the consolidation degree, $F(n)$ is a drain spacing factor, and $F_{\mathrm{w}}(n)$ is a drain spacing factor that incorporates well resistance. The time factor ratio is used to determine the increase of consolidation time due to well resistance. The value of $T_{h, w} / T_{h}$ is calculated by using Equation (6) proposed by Tran-Nguyen, Edil, and Schneider (2010), which was derived from the vertical drainage theory proposed by Hansbo (1979).

$\frac{T_{h, w}}{T_{h}}=1+\frac{(2 \pi / 3) L^{2}\left(k_{h} / q_{w}\right)}{\ln (n)-3 / 4}$

where, $n$ is $D / d_{w}$, and $d_{w}$ is the equivalent diameter.

\section{RESEARCH METHODS}

\subsection{The Structure of PVD}

PVD is a geocomposite material consisting of a filter made from geotextile and a core made from polymer. The filter is used to protect the core from soft soil infiltration, which clogs inside the drain, leading to decreased discharge capacity (Jang, Kim, and Lee, 2015). This research examined the discharge capacity of PVD-A and PVD-B harmonica cored samples, with the dimensions of 3 and $4 \mathrm{~mm}$ thickness $(t)$ and 100 $\mathrm{mm}$ width $(w)$. The physic and mechanic characteristics of the drains are shown in Table 1.

\subsection{Methods and Test Apparatus}

This research utilized a specifical apparatus developed by Chrismaningwang et al. (2020) to evaluate the PVD-PHD connection system's discharge capacity by adopting ASTM D4716, which discusses geosynthetic transmissivity (ASTM, 2001). The apparatus was designed to represent the field condition, where the lateral earth pressure confines the PVD and PHD, and surcharge preloading, respectively. 
Table 1. Physic and mechanic characteristics of PVD

\begin{tabular}{|c|c|c|c|}
\hline Characteristics & $\begin{array}{l}\text { Testing } \\
\text { standards }\end{array}$ & PVD-A & PVD-B \\
\hline \multicolumn{4}{|l|}{ Composite } \\
\hline $\begin{array}{l}\text { Thickness, } t \\
(\mathrm{~mm})\end{array}$ & $\begin{array}{l}\text { ASTM } \\
\text { D5199-99 }\end{array}$ & 3 & 4 \\
\hline Width, $w(\mathrm{~mm})$ & $\begin{array}{l}\text { ASTM } \\
\text { D5199-99 }\end{array}$ & 100 & 100 \\
\hline $\begin{array}{l}\text { Tensile } \\
\text { strength } \\
(\mathrm{kN} / \mathrm{m})\end{array}$ & $\begin{array}{l}\text { ASTM } \\
\text { D4595 }\end{array}$ & 2.53 & 2.55 \\
\hline Filter & & $\begin{array}{l}\text { Polyethylene } \\
\text { terephthalate }\end{array}$ & $\begin{array}{l}\text { Polyethylene } \\
\text { terephthalate }\end{array}$ \\
\hline $\begin{array}{l}\text { Thickness } \\
(\mathrm{mm})\end{array}$ & $\begin{array}{l}\text { ASTM } \\
\text { D5199-99 }\end{array}$ & $0.24-0.25$ & $0.24-0.25$ \\
\hline $\begin{array}{l}\text { Permeability } \\
(\mathrm{mm} / \mathrm{s})\end{array}$ & $\begin{array}{l}\text { ASTM } \\
\text { D4491 }\end{array}$ & 0.347 & 0.358 \\
\hline $\operatorname{AOS}(\mu \mathrm{m})$ & $\begin{array}{l}\text { ASTM } \\
\text { D4751 }\end{array}$ & $75-90$ & $75-90$ \\
\hline Core & & Polypropylene & Polypropylene \\
\hline $\begin{array}{l}\text { Mass per unit } \\
\text { area, } \mu\left(\mathrm{kg} / \mathrm{m}^{2}\right)\end{array}$ & $\begin{array}{l}\text { ASTM } \\
\text { D5261-92 }\end{array}$ & 0.48 & 0.52 \\
\hline $\begin{array}{l}\text { Elongation at } \\
\text { break (\%) }\end{array}$ & $\begin{array}{l}\text { ASTM } \\
\text { D4632 }\end{array}$ & 46 & 45 \\
\hline $\begin{array}{l}\text { Polymer } \\
\text { density, } \rho \\
\left(\mathrm{kg} / \mathrm{m}^{3}\right)\end{array}$ & $\begin{array}{l}\text { ASTM } \\
\text { D5261-92 }\end{array}$ & 898.54 & 898.54 \\
\hline
\end{tabular}

The test apparatus consisted of two main parts, namely cylinder and upper compression chambers. The cylinder compression chamber was made of $10 \mathrm{~mm}$ thick acrylic with $200 \mathrm{~mm}$ diameter and $500 \mathrm{~mm}$ height, complete with two steel pedestals and PVD holders. The confining pressure mechanism in this chamber implemented pressured water controlled by a constant device. The upper compression chamber was made from $10 \mathrm{~mm}$ thick steel with $470 \times 460 \times 700 \mathrm{~mm}$ and used as an outflow reservoir. The illustration of the apparatus is shown in Figure 1.

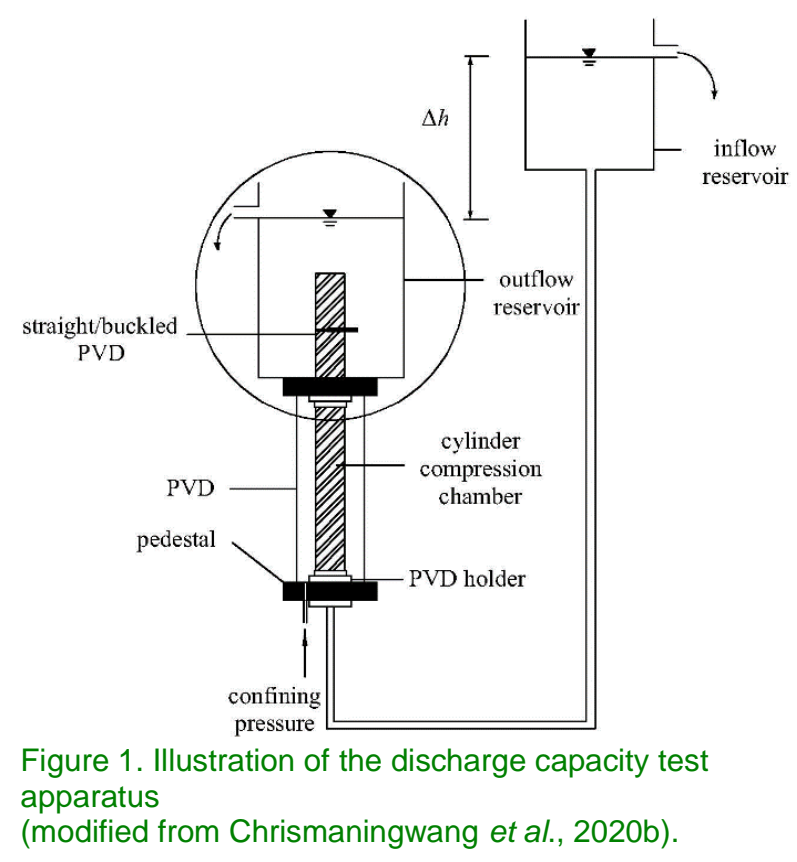

Comprehensive studies have been carried out to determine the effect of PVD deformation on discharge capacity (Ali, 1991; Jang, Kim and Lee, 2015; Bo et al., 2016). In infield practice, PVD deformation is a result of lateral earth pressure or soil preloading. This study focused on PVD deformation above the soil surface, buckled due to the soil preloading pressure or connection to PHD. All tests were conducted in $1 \mathrm{~m}$ length specimens using straight and buckled (tied with a cable tie) conditions on the upper side, as shown in Figure 2. The straight specimens are identified as PVD-A-St and PVD-B-St, while the buckled ones are PVD-A-Bc and PVD-B-Bc.

The specimens' setting is as follows: $500 \mathrm{~mm}$ length specimens were placed in the cylinder compression chamber, and the rest were extended to the box compression chamber. The buckled condition was obtained by folding the PVD at the height of $250 \mathrm{~mm}$ inside the outlet tank. Meanwhile, for the straight condition, it was kept at the initial position. All of the specimens were wrapped in latex membranes to separate them from the confining water. It was further subjected to stepwise confining pressures at a range of $50-200 \mathrm{kPa}$, with a $50 \mathrm{kPa}$ addition at every loading stage. The water flow mechanism is a constant head flow, and the variation of hydraulic gradient was acquired by adjusting the inlet tank. 


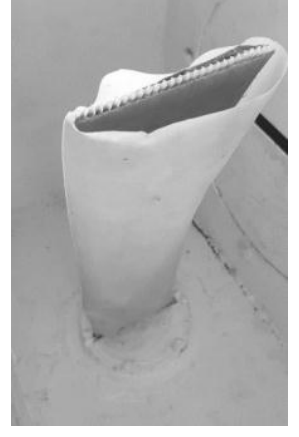

(a) Straight PVD
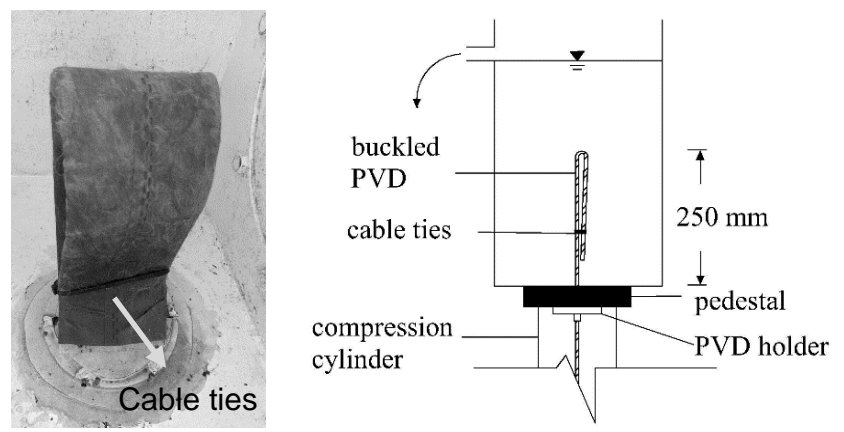

(b) Buckled PVD

Figure 2. Detail of outflow reservoir and sample configuration

A calibration test is used to determine a calibration curve that originated from the relationship of the flow rates and the head difference (ASTM, 2001). A calibration curve is a reference used to resolve the calibrated head difference $\left(\Delta h_{\text {cal }}\right)$, needed to determine the value of the corrected hydraulic gradient $\left(i_{\text {corr }}\right)$. Chrismaningwang et al. (2020) carried out a research on the apparatus's calibration test and determined $\Delta h_{\text {cal }}$ using Equation (7).

$\Delta h_{c a l}=0,0025 Q^{1,7163}$

The value of $i_{\text {corr }}$ is determined using Miura and Chai (2015) research as stated in Equation (8):

$i_{\text {corr }}=\frac{\Delta h-\Delta h_{c a l}}{L}$

The calculation showed that the values of $\Delta h_{\text {cal }}$ were noticeably small (between $8.9 \times 10^{-11}$ to $8.9 \times 10^{-10} \mathrm{~m}$ ) hence the insignificant effect of the apparatus on the specimen's in-plane flow indicates that the apparatus is eligible.

\section{RESULTS AND DISCUSSIONS}

\subsection{The Effect of Confining pressure $\left(\sigma_{c}\right)$ on The Discharge Capacity of Deformed PVD}

Figures 3 and 4 show the decline in discharge capacity due to the stepwise confining pressure under varied hydraulic gradients. The values of discharge capacity and $i_{\text {corr }}$ were obtained from Equations (1) and (8). According to preliminary studies, identical curve patterns were noticed for all specimens, with a decline in the discharge capacity due to the confining pressure (Yarahmadi, Gratchev, and Jeng, 2017; Chai et al., 1995). Meanwhile, the confining pressure escalated from 50 to $200 \mathrm{kPa}$. The average values of $q_{w}$ reduction for PVD-A-St, PVD-A-Bc, PVDB-St, and PVD-B-Bc are 62.54\%, 64.90\%, 42.37\%, and $40.49 \%$, respectively. The decrease of discharge capacity value is more critical when the hydraulic gradient is low in accordance with the theory proposed by preliminary studies (Bergado, Manivannan, and Balasubramaniam, 1996; Bo et al., 2016).

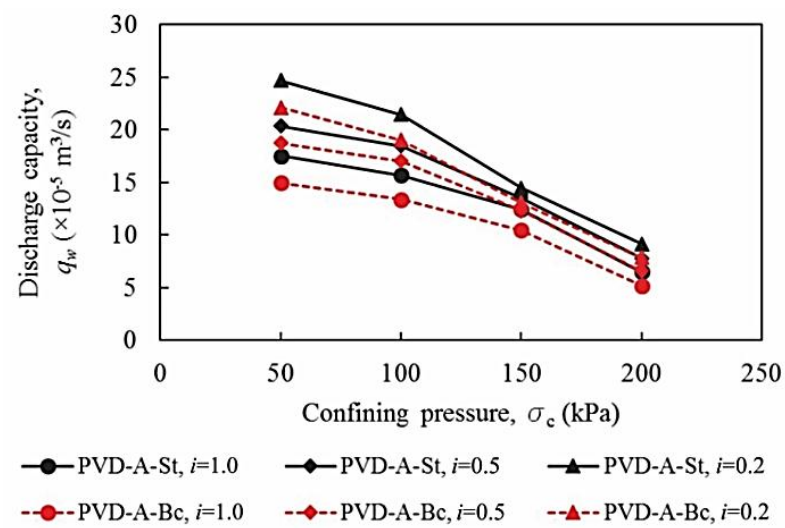

Figure 3. Discharge capacity values of PVD-A.

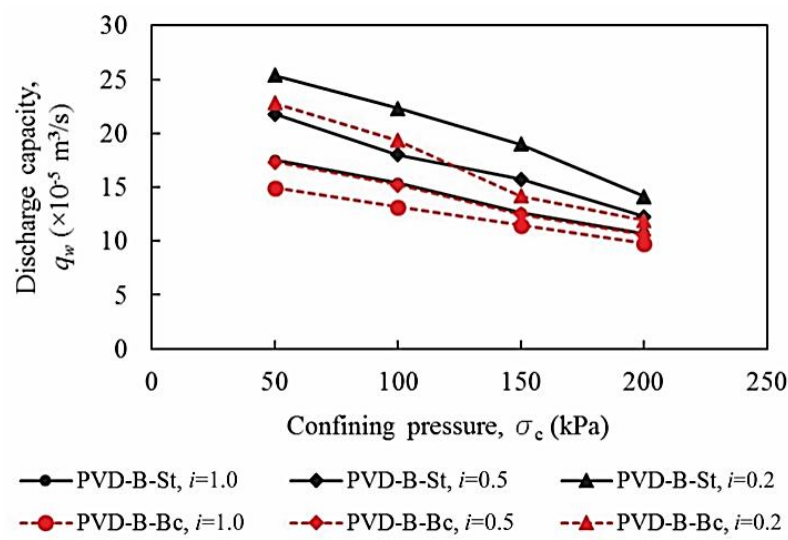

Figure 4. Discharge capacity values of PVD-B. 
The test results showed that the discharge capacity is higher on the straight samples. Furthermore, when the PVD-A and PVD-B were buckled by $16.24 \%$ and $13.09 \%$, the whole drainage area was obstructed, thereby leading to a discharge capacity reduction. Both specimens had the same filter and core material, although the PVD-B had higher discharge capacity values, presumably because the stiffness is more significant with greater thickness, which congenial with preliminary studies (Chai, Miura, and Nomura, 2004; Miura and Chai, 2015). These results showed that the thicker PVD were more resistant to confining pressure and deformation. However, all of the specimens were fulfill the criteria by having a $q_{w}$ value higher than $q_{\mathrm{w}(\mathrm{req})}$, which are $3.2 \times 10^{-6}$ to $4.8 \times 10^{-6} \mathrm{~m}^{3} / \mathrm{s}$ (Holtz, 1987; Bo, 2004; Chu, Bo, and Choa, 2004).

\subsection{Time Factors Ratio Analysis ( $\left.T_{h, w} / T_{h}\right)$}

The discharge capacity value is compulsory to determine the value of well resistance, which is used as a parameter in vertical drainage design. According to Holtz (1987), the well resistance reduces with a decrease in discharge capacity and an increase in consolidation time. The time factor ratio analysis is convenient to measure the consolidation time delay, which is influenced by well resistance. The values of discharge capacity acquired from the laboratory measurement were used to determine the time factors ratio, $T_{\mathrm{h}, \mathrm{w}} / T_{\mathrm{h}}$, by applying Equation (6). The time factors ratio analysis was conducted under several assumptions:

a) the horizontal permeability of surrounding soil $\left(k_{h}\right)$ is $1 \times 10^{-8} \mathrm{~m} / \mathrm{s}$,

b) the length of embedded PVD $(L)$ is $20 \mathrm{~m}$,

c) with $1 \mathrm{~m}$ spacing $(S)$ and triangular formation.

The relation between the drains' discharge capacity and the time factors ratio for straight and buckled PVD are shown in Figures 5 and 6, respectively. The buckled PVD has a more considerable consolidation time because of the higher $T_{\mathrm{h}, \mathrm{w}} / T_{\mathrm{h}}$ ratio, while those with greater thickness provided a lower time factors ratio. The increase in time factors ratio was more prominent in the buckled specimens, while those for the straight specimens are linear and smooth. The values of $T_{\mathrm{h}, \mathrm{w}} / T_{\mathrm{h}}$ for all specimens are plotted in Figure 7. Moreover, the value of $q_{\mathrm{w}(\mathrm{req})}$ obtained from Equation (3) applied on Equation (6) gave the value of $T_{\mathrm{h}, \mathrm{w}} / T_{\mathrm{h}}=1.19$. The analysis results showed that the increase in the time factor ratio was significant on PVD with a discharge capacity value less than $10^{-4} \mathrm{~m}^{3} / \mathrm{s}$. Therefore, it is concluded that the deformation on the upper side of PVD had a considerable effect on PVD performance.

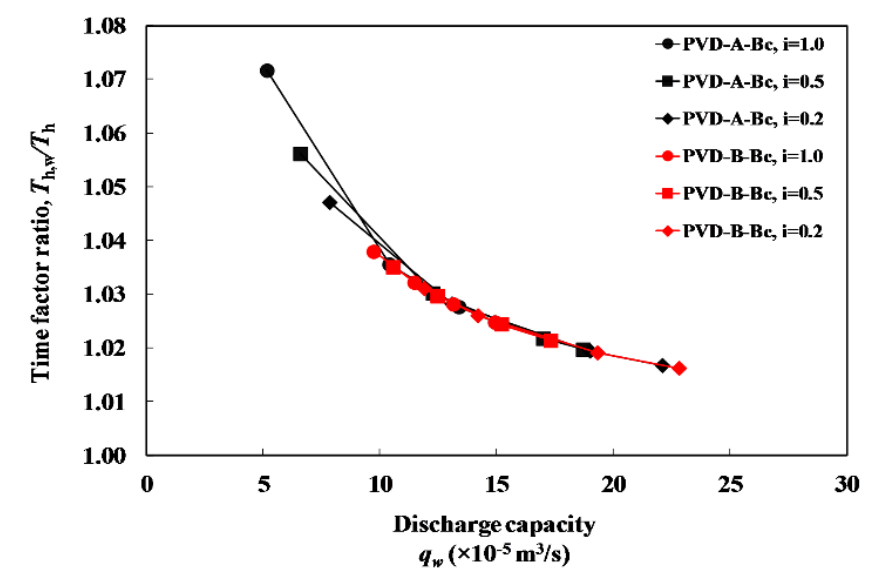

Figure 5. Ratio of $T_{h, w} / T_{h}$ on straight PVD

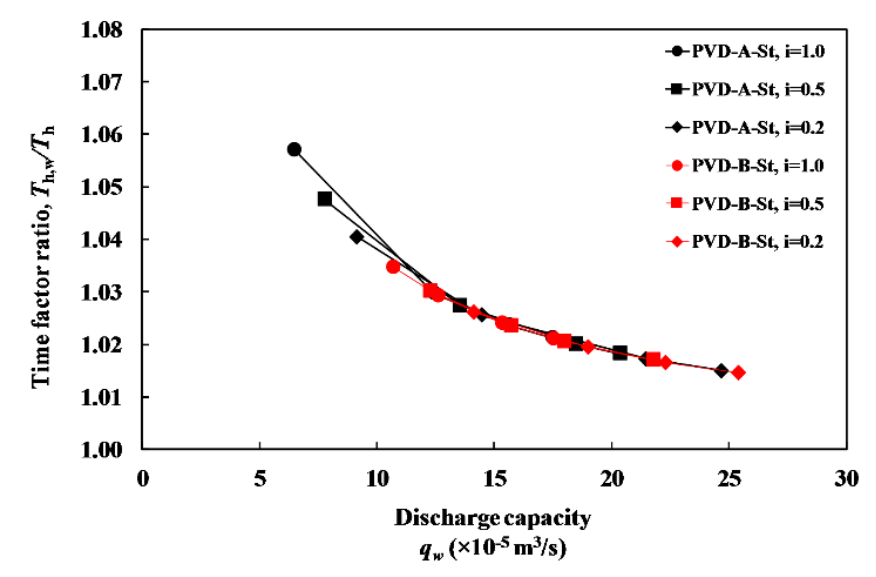

Figure 6. Ratio of $T_{h, w} / T_{h}$ on buckled PVD. 


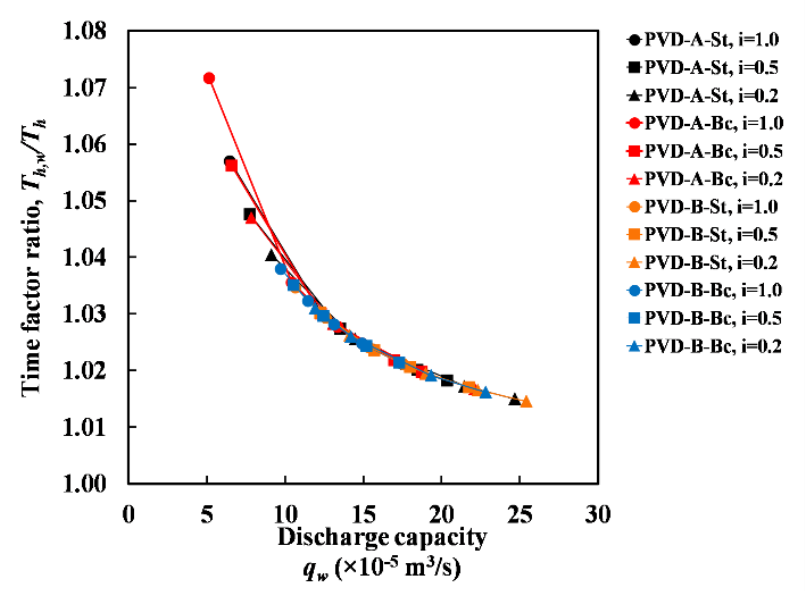

Figure 7. Ratio of $T_{\mathrm{h}, \mathrm{w}} / T_{\mathrm{h}}$ as a function of $q_{\mathrm{w}}$.

\section{CONCLUSIONS}

The discharge capacity is the key variable that defines PVD behavior considered in the calculation of well resistance, taken into account in the vertical drainage design. This study adopted ASTM D4716 to evaluate the significance of confining pressure and buckled deformation on PVD specimens' discharge capacity with different thicknesses to simulate infield practice conditions.

The test results showed that the thicker samples have higher discharge capacity with more critical reduction at lower hydraulic gradients. Straight PVD-A, buckled PVD-A, straight PVD-B, and buckled PVD-B have average $q_{w}$ reduction values of $62.54 \%, 64.90 \%, 42.37 \%$, and $40.49 \%$, respectively. The buckled specimens' discharge capacity is lower than the straight by approximately $13-16 \%$, thereby confirming that the deformation on the upper-side of PVD affected its performance. Nonetheless, all of the specimens were considered eligible as vertical drainage since the value of $q_{w}$ is larger than $q_{w(r e q)}$.

The $q_{w}$ values obtained from the experiments were employed as a parameter in a time factor ratio $T_{\mathrm{h}, \mathrm{w}} / T_{\mathrm{h}}$ analysis. The results showed that the deformed PVD has a higher time factor ratio, thereby leading to a consolidation time delay.

\section{DISCLAIMER}

The authors declare no conflict of interest.

\section{AVAILABILITY OF DATA AND MATERIALS}

All data are available from the corresponding author.

\section{ACKNOWLEDGMENTS}

The authors are grateful to the Soil Mechanics Laboratory of Universitas Gadjah Mada for accommodating the laboratory test. The authors are also grateful to the Ministry of Education and Culture of the Republic of Indonesia for supporting and funding of this research, as well as to PT. Teknindo Geosistem Unggul for their technical assistance.

\section{REFERENCES}

Ali, F.H., 1991. The Flow Behaviour of Deformed Prefabricated Vertical Drains. Geotextiles and Geomembranes, 10, pp.235-248.

ASTM, 2001. ASTM D4716, Standard Test Method for Determining the (In-Plane) Flow Rate per Unit Width and Hydraulic Transmissivity of Geosynthetic Using A Constant Head. West Conshohocken, PA, USA: ASTM International.

Barron, R.A., 1948. Consolidation of FineGrained Soils by Drain Wells. Proceedings of the American Society of Civil Engineers, 73(6), pp.811836.

Bergado, D.T., Manivannan, R. and Balasubramaniam, A.S., 1996. Proposed criteria for discharge capacity of prefabricated vertical drains. Geotextiles and Geomembranes, 14(9), pp.481-505.

Bo, M.W., 2004. Discharge capacity of prefabricated vertical drain and their field measurements. Geotextiles and Geomembranes, 22(1-2), pp.37-48.

Bo, M.W., Arulrajah, A., Horpibulsuk, S., Chinkulkijniwat, A. and Leong, M., 2016. Laboratory measurements of factors affecting discharge capacity of prefabricated vertical drain materials. Soils and Foundations, [online] 56(1), pp.129-137. Available at: http://dx.doi.org/10.1016/j.sandf.2016.01.010. 
Bourge`s-Gastaud, S., Blond, E. and Touze-Foltz, N., 2013. Multiscale transmissivity study of drain-tube planar geocomposites : effect of experimental device on test representativeness. Geosynthetics International, 20(3), pp.119-128.

Cai, Y., Qiao, H., Wang, J., Geng, X., Wang, P. and Cai, Y., 2017. Experimental tests on effect of deformed prefabricated vertical drains in dredged soil on consolidation via vacuum preloading. Engineering Geology, [online] 222, pp.10-19. Available at: http://dx.doi.org/10.1016/j.enggeo.2017.03.020.

Cascone, E. and Biondi, G., 2013. A case study on soil settlements induced by preloading and vertical drains. Geotextiles and Geomembranes, [online] 38, pp.51-67. Available at: http://dx.doi.org/10.1016/j.geotexmem.2013.05. 002.

Chai, J.-C., Miura, N., Sakajo, S. and Bergado, D., 1995. Behaviour of vertical drain improved subsoil under embankment loading. Soils and Foundations, 35, pp.49-61.

Chai, J., Miura, N. and Nomura, T., 2004. Effect of hydraulic radius on long-term drainage capacity of geosynthetics drains. Geotextiles and Geomembranes, 22, pp.3-16.

Chrismaningwang, G., Hardiyatmo, H.C., Adi, A.D. and Fathani, T.F., 2020a. Laboratory Measurements of Discharge Capacity Under Incremental Confining Pressure of Geosynthetic Drains. International Review of Civil Engineering (I.RE.C.E.), 11(September), pp.222-228.

Chrismaningwang, G., Hardiyatmo, H.C., Adi, A.D. and Fathani, T.F., 2020b. The effect of incremental confining pressure on the hydraulic properties of PVD. International Journal of GEOMATE, 19(73), pp.41-48.

Chu, J., Bo, M.W. and Choa, V., 2004. Practical considerations for using vertical drains in soil improvement projects. Geotextiles and Geomembranes, 22(1-2), pp.101-117.

Chung, S.G., Kweon, H.J. and Jang, W.Y., 2014. Observational method for field performance of prefabricated vertical drains. Geotextiles and Geomembranes, [online] 42(4), pp.405-416. Available at: http://dx.doi.org/10.1016/j.geotexmem.2014.06. 005.

Hansbo, S., 1979. Consolidation of Clay By BandShaped Prefabricated Drains. Ground Engineering, 12(5), pp.16-18, 21.

Hansbo, S., 1997. Aspects of vertical drain design : Darcian or non-Darcian flow. Geotechnique, 47(5), pp.983-992.

Holtz, R.D., 1987. Preloading with prefabricated vertical strip drains. Geotextiles and Geomembranes, 6(1-3), pp.109-131.

Holtz, R.D., Jamiolkowski, M.B., Lancellotta, R. and Pedroni, R., 1991. Prefabricated vertical drains : design and performance. London: CIRIA.

Indraratna, B. and Chu, J., 2005. Ground Improvement: Case Histories. London: Elsevier Ltd.

Jang, Y.S., Kim, B. and Lee, J.W., 2015. Evaluation of discharge capacity of geosynthetic drains for potential use in tunnels. Geotextiles and Geomembranes, [online] 43(3), pp.228-239. Available at: http://dx.doi.org/10.1016/j.geotexmem.2015.03. 001.

Jeon, H., 2014. Short-Term Compressive Properties and Transmissivity of Geonets. Textile Science and Engineering, 51(2), pp.96-100.

Koerner, R.M., 2005. Designing with Geosynthetics. 5th ed. New Jersey: Pearson Prentice Hall.

Mesri, G. and Lo, D.O.., 1991. Field performance of prefabricated vertical drains. In: Proceedings International Conference on Geotech Engineering for Coastal Development. Yokohama, pp.231-236.

Miura, N. and Chai, J.C., 2015. Discharge Capacity of Prefabricated Vertical Drains Confined in Clay. Geosynthetics International, [online] 7(2), pp.119-135. Available at: http://www.icevirtuallibrary.com/doi/abs/10.168 
0/gein.7.0169.

Da Silva, E.M., Justo, J.L., Durand, P., Justo, E. and Vázquez-Boza, M., 2017. The effect of geotextile reinforcement and prefabricated vertical drains on the stability and settlement of embankments. Geotextiles and Geomembranes, 45(5), pp.447-461.

Tran-Nguyen, H.H., Edil, T.B. and Schneider, J.A., 2010. Effect of deformation of prefabricated vertical drains on discharge capacity. Geosynthetics International, 17(6), pp.431-442.

Tripathi, K.K. and Nagesha, M.S., 2010. Discharge capacity requirement of prefabricated vertical drains. Geotextiles and Geomembranes, [online] 28(1), pp.128-132. Available at: http://dx.doi.org/10.1016/j.geotexmem.2009.09. 004.
Yarahmadi, N., Gratchev, I. and Jeng, D., 2017. The effect of thickness reduction on the hydraulic transmissivity of geonet drains using rigid and non-rigid fl ow boundaries. Geotextiles and Geomembranes, [online] 45(2), pp.48-57. Available at: http://dx.doi.org/10.1016/j.geotexmem.2016.11. 006.

Zhang, Z., Ye, G. and Xu, Y., 2018. Comparative analysis on performance of vertical drain improved clay deposit under vacuum or surcharge loading. Geotextiles and Geomembranes, [online] 46(2), pp.146-154. Available at: https://doi.org/10.1016/j.geotexmem.2017.11.00 2 . 
[This page is intentionally left blank] 